\title{
TIME, TRUTH, ACTUALITY, AND CAUSATION: ON THE IMPOSSIBILITY OF DIVINE FOREKNOWLEDGE
}

\author{
MICHAEL TOOLEY \\ University of Colorado at Boulder
}

\begin{abstract}
In this essay, my goal is, first, to describe the most important contemporary philosophical approaches to the nature of time, and then, secondly, to discuss the ways in which those different accounts bear upon the question of the possibility of divine foreknowledge. I shall argue that different accounts of the nature of time give rise to different objections to the idea of divine foreknowledge, but that, in addition, there is a general argument for the impossibility of divine foreknowledge that is independent of one's account of the nature of time.
\end{abstract}

\section{A FUNDAMENTAL DIVIDE: \\ STATIC VERSUS DYNAMIC VIEWS OF TIME}

\subsection{An Intuitive Characterization of the Divide}

The most fundamental divide between different philosophical theories concerning the nature of time is that between what are usually referred to, on the one hand, as tenseless theories of time, and, on the other, tensed theories - though some philosophers, and this is my own predilection, prefer to talk instead of a distinction between static theories of time and dynamic theories of time.

One way of describing this divide is in terms of different accounts of tensed concepts - that is, the concept of the present, and of other concepts that involve the concept of the present, such as the concept of the past and the concept of the future. Thus, according to tensed or dynamic approaches to the nature of time, tensed concepts are ontologically significant, either because there are special tensed properties that events can have or fail to have - including the property of presentness, and, on some 
accounts, also the properties of pastness and futurity - or, alternatively, because there are divisions between the past, the present, and the future, with regard to existence itself.

By contrast, according to tenseless or static approaches to the nature of time, there are no special properties of presentness, pastness, or futurity, nor is there any ontological divide between past, present, and future: events past, present, and future are all equally real.

How, then, are tensed concepts to be understood, according to tenseless or static approaches to the nature of time? The answer is that the term "now", and similar expressions such as "the present", along with present-tense endings on verbs, are all to be understood as pure indexical terms, on a par with the spatial indexicals "here" and "there". Thus, just as to say that something is happening here, rather than there, is neither to assign some special, 'spatially tensed' property to that event, nor to refer to some ontological gulf between things that are here and things that are there, but, rather, is simply to say what could equally be said by saying that the event in question is happening at this spatial location, so to say that an event is happening now is simply to say that the event is happening at this very moment, at this temporal location. Similarly, to say that an event happened in the past, or will happen in the future, is simply to say that the event is, respectively, either earlier than this very moment, or later than this very moment.

\subsection{Truth and Actuality: Simpliciter Versus Temporally-Indexed}

There is, however, what is to my mind a philosophically more important way of describing the difference between static and dynamic accounts of the nature of time. If there are tensed properties of presentness, pastness, and futurity, then events will change with respect to those properties: an event will initially have the property of futurity, will lose it and acquire the property of presentness, which it will have for only a moment, and it will then lose that property, and acquire the property of pastness. Which tensed propositions are true with regard to a given event will therefore depend upon what time it is.

Similarly, if there is some ontological divide among past events, present events, and future events, then there will be times as of which 
a given event is not actual, is not real, and other times when it is actual. Consequently, propositions about a given event will, once again, not always have the same truth-value.

Compare the situation if a static or tenseless view of time is correct. The truth-value of a proposition will, in that case, not depend upon what time it is, since a given event cannot lie on different sides of an ontological divide between existence and nonexistence at different times: all events, past, present, and future, are equally real. Nor, if there are no special tensed properties, is there any possibility for an event to differ with regard to what tensed properties it has at different times.

It is true that what tensed sentences are true will depend upon what time it is. At one moment, it will be true to say that event $\mathrm{E}$ is now happening, while at a later moment it will be true instead to say that event E has happened, and not true to say that it is now happening. But that doesn't mean that there is some proposition that has gone from being true to being false. For if the term "now" is, as defenders of tenseless approaches to time hold, simply a temporal indexical, then the utterance of a given type of tensed sentence at different times must necessarily express different propositions, since the temporal indexical term - such as "now" - refers indexically to different times when the sentence is uttered at different times.

The upshot is this. According to static or tenseless views of time, the appropriate concept of truth is what might be called truth simpliciter, understood as a relation between propositions and what is actual simpliciter. For if all events, past, present, and future are equally real, and there are no special tensed properties, then the totality of what is actual cannot differ from one moment to another, and because that cannot differ, what propositions are true cannot differ from one moment to another. The only relevant notions of truth and actuality, therefore, are the concept of what is true simpliciter, and the concept of what is actual simpliciter: there is no place for any temporally indexed concept of truth, or for any temporally indexed concept of what is actual.

The situation is very different given a dynamic or tensed approach to the nature of time, since if there is some ontological divide between past, present, and future events with respect to reality, or if there are special tensed properties that objects can acquire and lose, then a given proposition can have different truth values at different times. So, although the 
notion of truth simpliciter may also be needed - I have argued elsewhere that it is - a temporally indexed notion of truth - the concept of truth at a time - is absolutely indispensible given any tensed or dynamic approach to the nature of time. Similarly, a temporally indexed notion of actuality is needed - the concept of what is actual as of a given time - as can be seen in either of two ways. First of all, given a correspondence theory of truth, what propositions are true cannot vary from one time to another unless the totality of what is actual as of one time differs from the totality of what is actual as of another time. Secondly, if there are special tensed properties, then the tensed states of affairs that any given event is involved in must differ between some times: at one time, the state of affairs that is event E's having the property of presentness belongs to the totality of what is actual, whereas, at other times, it does not, having been replaced by the state of affairs that consists of event E's having instead the property of pastness. Alternatively, if the dynamic nature of the world derives instead from some ontological divide between past, present, and future events, then the totality of what is actual as of one time will include event $\mathrm{E}$, whereas the totality of what is actual as of some other time may very well not include event $\mathrm{E}$.

To sum up, then, there are, on the one hand, the absolute concepts of truth simpliciter and of what is actual simpliciter, and, on the other hand, there are the temporally indexed notions of truth at a time, and of the totality of what is actual as of a given time. The latter pair of notions is crucial for any tensed or dynamic view of the nature of time, whereas only the former, absolute notions of truth and of actuality play any role in the case of tenseless or static views of the nature of time.

\section{DIFFERENT THEORIES OF THE NATURE OF TIME}

\subsection{Static Theories of the Nature of Time}

Static theories of the nature of time do differ on certain matters, of which the most important are perhaps the following:

(1) Precisely what account is to be given of tensed sentences?

(2) What account is to be given of the later than relation, and of the 
direction of time? Is the later than relation a basic, unanalyzable relation? Is the direction of time to be explained in terms of some concept in physics, such as the direction of increase in entropy, or the expansion of the universe? Or is the direction of time to be analyzed in terms of the relation of causation?

These differences, however, philosophically important though they are, are not crucial, I think, in the context of questions concerning the possibility of divine foreknowledge. What is important in that context is the thesis, shared by all static approaches to time, that all events, past, present, and future, are equally real, and that there cannot be any change, over time, with regard to the totality of what is actual.

\subsection{Dynamic Theories of the Nature of Time}

Tensed or dynamic theories of the nature of time take a number of very different forms, of which the most important, I think, are the following.

\subsubsection{The 'Growing Block' View}

This is the view that the states of affairs that are actual as of any given time are the states of affairs that exist at that time plus the states of affairs that exist at earlier times, but not the states of affairs that exist at later times. In short, past and present events are actual as of a given time, but not future events.

On this view there is no special, intrinsic property of presentness. Presentness is, instead, a structural property: the states of affairs that are present at a given time are the states of affairs that are the latest among the totality of states of affairs that are actual as of the time in question.

\subsubsection{Storrs McCall's 'Concrete Possible Futures' View of Time}

A different view, but one that is in most respects closely related to growing block views, has been advanced by the Canadian philosopher, Storrs McCall (1994). His idea is to treat future possibilities in a way that is similar to that in which David Lewis treated all logical possibilities, so 
that just as Lewis held that each logically possible state of affairs exists somewhere in a concrete possible world, so McCall holds that possible future states of affairs all exist as concrete states of affairs. What happens, then, is that as time passes, there is a moment when all of the branches that existed at that time drop out of existence, except for a single branch. Before that happens, there were multiple possibilities for branching at the time in question, and because of that, it was indeterminate what would be the case at that time. The present is thus the point at which the indeterminacy that existed concerning what would be the case at the time in question is replaced by a single, determinate state of affairs.

As in the case of the growing block view, then, presentness, rather than being an intrinsic property of events, is a structural property: an event lies in the present when it lies at the point where the branching representing future possibilities begins.

\subsubsection{Presentism}

This is the view, as I would characterize it, that the only states of affairs that are actual as of a given time are the states of affairs that exist at that time. So stated, the question arises as to how any propositions about the past can be true. Advocates of presentism have attempted to answer that question in various ways, but the main one involves the idea that states of affairs that exist at any given time are not restricted to what might be called 'present tense' states of affairs: there are also past tense states of affairs, such as the state of affairs that consists of Caesar's having crossed the Rubicon, and, perhaps also, future tense states of affairs, such as the first unicorn being created five years from now.

Though this position is rather popular, especially in the United States, I believe it is open to decisive objections. In particular, I would argue, first, that the presentist can offer no satisfactory account of the concepts of the past and of the future; secondly, that on presentism there are no truthmakers for propositions about the past; and thirdly, that the presentist cannot offer a satisfactory account of cross-temporal relations, including causation. 


\subsubsection{The 'Moving Now' View}

A final tensed view that is interesting, but not very popular today, is very close to tenseless or static views of time in two respects. First of all, it involves the claim that all events, past, present, and future, are actual as of every given moment. Secondly, it claims that events are temporally ordered by a later than relation - a relation that can either be taken as primitive, or analyzed in one of the ways adopted in static accounts of the nature of time.

How, then, does this view of time differ from static views of time? The answer is that it is claimed that there is a special, intrinsic property of presentness that moves along the series of events ordered by the later than relation, so that every event has this intrinsic property of presentness for a moment. Before it acquires that property, an event lies in the future. Once it loses that property, it lies in the past. The passage of time consists, then, in the movement of this property: it is this movement that transforms what would otherwise be what McTaggart referred to as the 'B-series' into McTaggart's 'A-series'.

\section{THE ONTOLOGICAL STATUS OF FUTURE CONTINGENT EVENTS}

From a general metaphysical perspective, the crucial divide in the philosophy of time is that between static theories and dynamic theories. It seems to me, however, that with regard to issues raised by the idea of divine foreknowledge, the crucial divide is a different one - namely, to express it in ontological terms, between views on which future states of affairs are either actual simpliciter, or else actual as of the present moment, and views on which neither of those things is the case. Or, alternatively, to express it in semantical terms, the crucial divide with regard to issues raised by the idea of divine foreknowledge is that between views of the nature of time on which propositions about future contingent events are either true or false, simpliciter, or else true or false at the present moment, and views on which neither of these things is the case, since propositions about future contingents, rather than being true or false, 
or true or false at the present time, have, instead, the third truth-value, namely, indeterminacy.

If this is right, the crucial division is between, on the one hand, static views of the nature of time and the moving Now view, and, on the other, the growing block view and McCall's concrete-possible-futures view. The main thing that I want to do in the remainder of this talk, then, is to focus on two different problems that arise for divine foreknowledge, one of which arises if future events are real, and the other of which arises if they are not.

\section{HUMAN FREEDOM IN \\ A WORLD WITH TENSELESS TIME}

Before doing that, however, I want to mention briefly an argument that is sometimes advanced on the basis of the assumption that a static or tenseless view of time is true. It is an argument that, if correct, would mean that there would be no need to consider static or tenseless approaches to the nature of time in a context where we are interested in the idea of divine foreknowledge of contingent future events.

\subsection{An Argument for Logical Fatalism}

The argument in question can be expressed as follows:

(1) A static or tenseless view of time is correct.

(2) Let $p$ be some proposition about a future event, such as the proposition that John will perform action $\mathrm{A}$, where $\mathrm{A}$ is some action that can be performed at time $t$ in the year 2012 .

(3) According to a static or tenseless view of time, every proposition is either true simpliciter, or else false simpliciter.

(4) Therefore, either $p$ is true, or $p$ is false.

(5) If a static or tenseless view of time is correct, the truth-value of a proposition never changes.

(6) If the truth-value of a proposition never changes, then either a given proposition is always true, or it is always false. 
(7) So if $p$ is true, then $p$ is true at all times; while if $p$ is false, then $p$ is false at all times.

(8) Hence, if $p$ is true, then $p$ is true now; while if $p$ is false, $p$ is false now.

(9) Therefore, either it is now true that John will perform action A, or it is now false that John will perform action A.

(10) If it is now true that John will perform action A, then it is impossible for John not to perform action A.

(11) If it is impossible for John not to perform action A, then John is not free in a libertarian sense with regard to the choice of whether to perform action $\mathrm{A}$, or to refrain from performing action $\mathrm{A}$.

(12) If it is now false that John will perform action A, then it is impossible for John to perform action A.

(13) If it is impossible for John to perform action A, then John is not free in a libertarian sense with regard to the choice of whether to perform action $\mathrm{A}$, or to refrain from performing action $\mathrm{A}$.

(14) Therefore, either way, John is not free in a libertarian sense with regard to the choice of whether to perform action $\mathrm{A}$, or to refrain from performing action $\mathrm{A}$.

(15) In general, no one is ever free in a libertarian sense with regard to the choice of whether to perform a given action A, or to refrain from performing that action.

\subsection{The Unsoundness of this Argument}

Notice that if this argument were sound, it would show not only that a static or tenseless view of time is incompatible with libertarian free will, but also that such a view of time is incompatible with there being any indeterministic events. For a precisely parallel argument could be used to show, for example, that if an atom undergoes decay at time $t$, then it was logically determined that it would do so.

The argument, however, is unsound. The error occurs at step (6), where the following premise is used:

If the truth-value of a proposition never changes, then either a given proposition is always true, or it is always false. 
The problem with this premise is that it imports into a static or tenseless view of time the notion of truth at a time. Given a static or tenseless approach to the nature of time, however, the notion of truth at a time is either incoherent, or, at least, has no application to the world. For the notion of truth at a time only makes sense if the idea of being actual as of a time makes sense, and given a static or tenseless approach to time, no sense can be assigned to a temporally-indexed concept of what is actual.

Another way of putting the point is this. On a static or tenseless view of time, the truthmaker for a proposition such as that John will perform action $\mathrm{A}$, defined as a certain action that can be performed at time $t$ in the year 2012 is a state of affairs that exists at the time in question in the year 2012. If one says that the proposition in question is now true, that is naturally interpreted as saying that a state of affairs now exists that makes the proposition true. But the latter is not the case: there is no such state of affairs. The only truthmaker is the state of affairs that consists of John's performing action A at time $t$ in the year 2012, and the fact that John performs that action does nothing at all to make it the case that, before he performed that action, he could not have refrained from performing it.

\section{DIVINE FOREKNOWLEDGE AND THE REALITY OR UNREALITY OF FUTURE CONTINGENT EVENTS}

Let us now consider what potential problems there are for the possibility of divine foreknowledge, given different philosophical accounts of the nature of time. Basically, there are three questions that we need to answer. First of all, how do things stand if the growing block view of time is correct? According to that view, future contingent events are not real, are not actual, as of earlier times. If that is the case, what are the implications for the possibility of divine foreknowledge of future contingent events?

Secondly, there is Storrs McCall's concrete-possible-futures view of time. Here, rather than there being no future events that are actual as of earlier times, all future events are actual, but so, equally, are all future possibilities, and there is nothing in that plethora of concrete future possibilities that picks out the one pathway through all those future 
branchings as the unique sequence of events that will actually obtain. So what implications does this picture have for the possibility of divine foreknowledge?

Finally, how do things stand given a static or tenseless view of time, or on a moving Now view? According to a static or tenseless view, future contingent events are actual simpliciter, while according to a moving Now view, all events, past, present, and future, except for those that involve the tensed property of presentness, are actual as of every moment. So on either a static view of time, or a moving Now view, one has neither an absence of future contingent states of affairs, as on the growing block view, nor a multitude of concrete, future possibilities, with nothing to mark out the actual future, as on Storrs McCall's concrete-possible-futures view: one has, instead, just the actual future events, and so one does have events that could in principle be related to divine foreknowledge. Is divine foreknowledge possible, then, given either of these views?

\section{DIVINE FOREKNOWLEDGE, COUNTERFACTUALS, AND CAUSATION}

What is involved in divine foreknowledge? On the face of it, there would seem to be three ways in which a person could have knowledge of future events. First of all, the person could be an agent who had the power to bring about the future event in question, and could decide to do that. Knowing what he had decided to attempt to do, and knowing that he had the power to do that, he would be in a position to know that the future event in question would occur.

Secondly, if the world contained deterministic laws of nature, and if a person had knowledge of relevant laws of nature, and of the present state of the world, that person would be in a position to draw conclusions about what future events would occur.

But when one is concerned with divine knowledge of future contingent events, such as what some agent with libertarian free will is going to do, neither of the two possibilities just mentioned apply: the actions of a free agent are not determined, either by God's actions, or by the operation of laws of nature. So what other possibility is there? 
A third possibility that certainly springs to mind is that future contingent events could cause corresponding beliefs that are present in the mind of God at an earlier time - indeed, at all earlier times.

This third possibility requires backward causation, and so one might wonder whether there is some other possibility.

Here is an argument, however, in support of the conclusion that divine foreknowledge of future contingent events does require causation running from those future contingent events to beliefs in the mind of God:

(1) Divine foreknowledge requires that God's beliefs about the future are counterfactually dependent upon the future events in question, since if some future event had not occurred, God would not have believed that it was going to occur.

(2) There are two main approaches to counterfactuals. First, there are the similarity-across-possible-worlds accounts, advanced by Robert Stalnaker (1968) and David Lewis (1973), according to which, on Lewis's version, the counterfactual proposition that if $p$ were true, $q$ would be true, is true in the actual world if there is a possible world in which both $p$ and $q$ are true that is closer to the actual world than any possible world in which $p$ is true but $q$ is false. Secondly, there are causal approaches to counterfactuals advocated by, among many others, Frank Jackson (1977) and Igal Kvart (1986).

(3) Jonathan Bennett (1974) and Kit Fine (1975), in early reviews of David Lewis's book Counterfactuals, argued that a similarity-across-possible-worlds approach to counterfactuals leads to incorrect assignments of truth-values to certain counterfactuals. Lewis (1979), a few years later, set out a method of avoiding the specific objections that Bennett and Fine advanced. But it can be shown that their objections can be modified to produce objections that cannot be blocked (Tooley, 2003). The conclusion, in short, is that similarity-across-possible-worlds approaches to counterfactuals are open to decisive objections.

(4) The upshot is that there does not appear to be any viable alternative to some sort of causal account of counterfactuals, so that, given that God's beliefs would have to be counterfactually dependent upon future contingent events, we have the following conclusion:

Divine foreknowledge of future contingent events requires that those events causally give rise to God's beliefs about them. 


\section{DIVINE FOREKNOWLEDGE AND THE GROWING BLOCK VIEW OF TIME}

Given that conclusion, how do things stand if a growing block view of time is correct? To answer that question, one has to ask how the actuality of events is related to causation.

In the argument that I offered in Time, Tense, and Causation for a growing block view of time, I attempted to show that the postulates that provide a correct analysis of causation can only be satisfied in a world where causes and their effects are related in an asymmetric way to what is actual. In particular, I argued that, on the one hand, the effect of a cause cannot be actual as of the time of its cause, while, on the other hand, a cause must be actual as of the time of its effect.

Put intuitively, the former must be the case if a cause is to bring its effect into existence, while the latter is required since it must be true at the time of the effect that it had a certain cause, and this cannot be so at that time unless both the effect and its cause are actual as of the time of the effect.

But if this is right, then, on a growing block view of the nature of time, future contingent events cannot causally give rise to earlier beliefs in the mind of God, since no future contingent event is actual as of any earlier time.

The conclusion, in short, is that the combination of a growing block view of time with what appear to be plausible claims about when a cause and its effect are actual poses a problem for the idea of divine foreknowledge.

\section{DIVINE FOREKNOWLEDGE \\ AND THE CONCRETE-POSSIBLE-FUTURES VIEW OF TIME}

On Storrs McCall's concrete-possible-futures account of the nature of time, all of the future contingent events that will be actual future events are actual as of earlier times. So there could be a causal connection between all of those events and beliefs in the mind of God.

But the problem is this. Let $t$ be any future time, and let A and B be possible future events that, if they occur, will occur at time $t$. Suppose 
that event A will actually occur at time $t$, and that B will not. It could be the case that the concrete future possibility that is A will give rise to a belief in the mind of God that A will occur, while the concrete future possibility that is B will not give rise to a belief in the mind of God that B will occur. But what could possibly ensure that this will be the case? It seems to me that there is no answer to this question. The thing in question could occur, but if it did it would be a pure accident. For if there were something in the world that could ensure that the future possibilities that will later be the ones that are realized will give rise to corresponding beliefs in the mind of God, there would have to be something in what was actual as of any relevant time that marked out just those concrete future possibilities, something that singled them out as the ones that would be realized, But on McCall's model of the nature of time, there is, by definition, nothing that does this.

Finally, I also think that McCall's concrete-possible-futures view of time is open to strong objections. For one thing, what future possibilities exist at any given time logically supervenes on the totality of the states of affairs that exist at that time, together with laws of nature, so there is absolutely no reason to postulate concrete future possibilities.

McCall's response to this objection is that, rather than viewing future possibilities as logically supervenient upon laws of nature plus present states of affairs, one can instead view laws of nature as logically supervenient upon future possibilities. But the latter idea is open to two very strong objections. The nomological possibilities that exist at any one time will suffice to fix what laws of nature there are, but then what makes something a law involves an infinite set of states of affairs, and this in turn makes it extremely improbable that any laws will exist. So the result of McCall's proposal is that there cannot be any solution to the problem of justifying induction.

Secondly, the situation is made worse by the fact that, for any two future times that one picks, the concrete possibilities that exist at those times must define precisely the same set of laws of nature. If laws of nature were primary, this would pose no problem at all. But if it is concrete future possibilities that are, instead, primary, then it is an inexplicable cosmic coincidence that the concrete future possibilities that exist at each of an infinite number of future times all logically determine precisely the same laws of nature. 


\section{DIVINE FOREKNOWLEDGE AND BACKWARD CAUSATION}

Let us now consider how things stand with regard to the possibility of divine foreknowledge if either a static or tenseless view of time is correct, or a moving Now account.

If it is the case either that future events are actual as of the present moment, as the moving Now account of time holds, or, as static approaches to time maintain, future events are actual simpliciter, and a temporallyindexed view of actuality is metaphysically mistaken, then there is no initial barrier to God's having true beliefs about future contingent events, since there are events that are either actual simpliciter, or actual as of the relevant time, that could, barring any problems, causally give rise to God's beliefs.

The causation in question would, of course, be temporally backward causation, and some philosophers, such as Hugh Mellor in his books Real Time (1980), The Facts of Causation (1995), and Real Time II (1998), have argued that backward causation is logically impossible.

There is a central problem that afflicts at least most such arguments, however - namely, that they attempt to show that backward causation is logically impossible by first showing that causal loops are logically impossible, and then by arguing that if backward causation were logically possible, causal loops would also be logically possible. But the second part of this type of argument is very difficult to defend, since there certainly seem to be logically possible worlds that contain backward causation, but in which causal loops are nomologically impossible.

In Time, Tense, and Causation, I attempted to show that backward causation, even when it did not give rise to causal loops, was logically impossible. The argument that I offered, however, also supported a growing block view of time, and so an appeal to that argument cannot be combined with either a tenseless view of time, or a moving Now view.

The upshot is that it is not clear that divine foreknowledge can be ruled out via an appeal to any proof of the general impossibility of backward causation. 


\section{DIVINE FOREKNOWLEDGE AND THE POSSIBILITY OF UNDERCUTTING CAUSAL LOOPS}

Even if such arguments for the logical impossibility of backward causation can be shown to be unsound, however, this does not eliminate a nearby potential problem for divine foreknowledge. The reason is that even if backward causation is logically possible, it may be that causal loops are not.

In his paper "The Paradoxes of Time Travel" $(1976,149)$, David Lewis describes the following time travel case:

Consider Tim. He detests his grandfather, whose success in the munitions trade built the family fortune that paid for Tim's time machine. Tim would like nothing so much as to kill Grandfather, but alas he is too late. Grandfather died in his bed in 1957, while Tim was a young boy. But when Tim has built his time machine and traveled to 1920 , suddenly he realizes that he is not too late after all. He buys a rifle; he spends long hours in target practice; he shadows Grandfather to learn the route of his daily walk to the munitions works; he rents a room along the route; and there he lurks, one winter day in 1921, rifle loaded, hate in his heart, as Grandfather walks closer, closer, ....

A serious problem is clearly visible. Since Grandfather, in Lewis's story, dies in bed in 1957, evidently Tim, for some reason, did not succeed in killing Grandfather. But might he not have succeeded? Must it not have been possible for him to succeed? But if he had, and if we assume - as is part of Lewis's story - that Grandfather had not yet fathered the son who was Tim's father - then Tim would, in this counterfactual variant on Lewis's story, have undercut the causal chain leading to his own existence. So we would have a self-undercutting causal chain: Tim's killing of Grandfather would mean no more Grandfather, and, therefore, no father, and, therefore, no Tim.

The problem, in short, is that even if backward causation in general is not logically impossible, if the world is one where backward causal processes can connect up with forward causal processes, and vice versa, then there is the possibility of causal loops. Some of those causal loops may be self-supporting ones, which seems puzzling. Much more threatening, however, are causal loops of the self-undercutting variety. Indeed, mightn't it be argued that such self-undercutting causal loops entail con- 
tradictions: if Tim kills Grandfather, then Tim beings it about that Tim doesn't exist.

Lewis argues that the counterfactual variant does not generate such consequences:

If you suppose Tim to kill Grandfather and hold all the rest of his story fixed, of course you get a contradiction. But likewise if you suppose Tom to kill Grandfather's partner and hold the rest of his story fixed-including the part that told of his failure-you get a contradiction. If you make any counterfactual assumption and hold all else fixed you get a contradiction. The thing to do is rather to make the counterfactual supposition and hold all else as close to fixed as you consistently can. That procedure will yield perfectly consistent answers to the question: what if Tim had killed Grandfather? In that case some of the story that I told would not have been true. Perhaps Tim might have been the time-traveling grandson of someone else. Perhaps he might have been the grandson of a man killed in 1921 and miraculously resurrected. Perhaps he might have been not a time-traveler at all, but rather someone created out of nothing in 1920 and equipped with false memories of a personal past that never was. It is hard to say what is the least revision of Tim's story to make it true that Tim kills Grandfather, but certainly the contradictory story in which the killing both does and doesn't occur is not the least revision. Hence it is false (according to the unrevised story) that if Tim had killed Grandfather then contradictions would have been true. $(1976,152)$

Is Lewis's response satisfactory? I think that it is not, and the reason is this. First of all, Lewis's discussion of what would be the case if Tim killed Grandfather makes use of his own similarity-across-possible-worlds approach to counterfactuals: what would happen is a matter of what is the case in the closest possible worlds in which Tim kills Grandfather. But such an approach to counterfactuals is demonstrably unsound. Secondly, if one switches to a causal approach to such counterfactuals, what would have been the case if Tim killed Grandfather is fixed by what follows in virtue of causal laws from the proposition that Tim killed Grandfather combined with propositions that describe the minimally modified world at the time in question, or shortly before it, which is such that Tim kills Grandfather. But when this approach to counterfactuals is adopted, the combination of causal laws and the propositions describing that minimally modified world certainly seem to entail Tim's non-existence. 
This whole question certainly needs to be looked at in a much more detailed way than I have just done. My point, however, is that this question is crucial for the question of the possibility of divine foreknowledge. For if, for example, God at some time has foreknowledge of the fact that a person, John, will perform action A at time $t$ in 2012, and has that foreknowledge because the state of affairs that is John's performing action A at time $t$ in 2012 brings about, via backward causation, God's belief that John will perform action A at time $t$ in 2012, then God, at the earlier time, has the power to make a contradiction true, for being omnipotent, he certainly has the power to prevent John from performing action A at time $t$ in 2012.

The argument, in short, is this. Assume the following thesis, which is to be refuted:

(1) Divine foreknowledge is possible because (a) it is possible either that a static or tenseless view of time is right, or that a moving Now view of time is right, (b) on either view, there are future events that are either actual simpliciter, or actual as of earlier times, and (c) backward causation is logically possible, so that God can have foreknowledge of a future state of affairs, S, by having beliefs that are caused by $\mathrm{S}$.

The refutation of (1) now proceeds as follows:

(2) God's omnipotence makes it possible for him to intervene at the earlier time to prevent the later state of affairs $S$ from occurring.

(3) Given a correct, causal account of the relevant counterfactuals, it follows that if God were to act to prevent the later state of affairs $S$, it would be true both that $S$ will occur and that $S$ will not occur, and so a contradiction would be true.

(4) There cannot be true contradictions.

(5) Hence (1) is false. The defense of the possibility of divine foreknowledge proposed there cannot be correct. 


\section{THE GENERAL APPLICABILITY OF THIS FINAL OBJECTION}

I have directed this last argument against the conjunction of the proposition that divine foreknowledge is logically possible with the proposition that future events are either actual simpliciter, or actual as of the present moment. In fact, however, the objection applies regardless of which view of the nature of time one embraces. For on any view of time, divine foreknowledge requires that contingent future events can give rise to beliefs, or belief-like states, in the mind of God, and God, being omnipotent, can then act on the world to bring about a state of the world at some time prior to the contingent, future event in question, where the state is such as to rule out the occurrence of the contingent, future event in question. Regardless of the view that one adopts concerning the nature of time, then, divine foreknowledge would entail God's having the power of making contradictions true. But it is logically impossible for contradictions to be true, and so it is logically impossible for there to be such a power. Accordingly, divine foreknowledge is logically impossible.

\section{SUMMING UP}

1. With regard to the possibility of divine foreknowledge, the crucial division with respect to philosophical views on the nature of time is between, on the one hand, views according to which future states of affairs are actual, or else actual as of earlier times, and, on the other hand, views according to which there are no determinate future events that are actual, or actual as of earlier times.

2. There are good reasons for holding that divine foreknowledge of future contingent events that are neither causally determined nor caused by God requires that those future events causally give rise to beliefs in the mind of God at earlier times.

3. Causation is either a relation between states of affairs both of which are actual simpliciter, or else a relation where the cause is actual as of the time of its effect.

4. It follows, given a growing block view, that backward causation is not logically possible. 
5. On Storrs McCall's concrete-future-possibilities view of time, the problem is that there is nothing that can make it the case that those concrete future possibilities that will ultimately be realized give rise to corresponding beliefs in the mind of God.

6. If either the moving Now view of time, or a static or tenseless view of time is correct, then there are future states of affairs that either are actual, or else actual as of earlier times, so if backward causation is logically possible, it initially looks as if future states of affairs can causally give rise to corresponding beliefs in the mind of God. But now the problem is that, because of God's omnipotence, undercutting causal loops are possible, and given a sound account of the truth conditions of counterfactuals, it appears to follow that God would have the power to make contradictions true. Since nothing can have that power, this account of the possibility of divine foreknowledge also appears untenable.

7. The argument based on the idea of undercutting causal loops is not restricted to the combination of divine foreknowledge with views of the nature of time according to which contingent, future events are either actual simpliciter, or actual as of earlier times. It is an argument against the possibility of divine foreknowledge regardless of what view one adopts concerning the nature of time

8. Overall Conclusion: The idea of divine foreknowledge gives rise to very serious problems, and there is a very plausible, and completely general argument that appears to show that divine foreknowledge is logically impossible.

\section{BIBLIOGRAPHY}

Bennett, Jonathan, 1974, "Counterfactuals and Possible Worlds," Canadian Journal of Philosophy, 4, 381-402.

Fine, Kit, 1975, “Critical Notice - Counterfactuals," Mind, 84, 451-8.

Jackson, Frank, 1977, "A Causal Theory of Counterfactuals," Australasian Journal of Philosophy, 55, 3-21.

Kvart, Igal, 1986, A Theory of Counterfactuals, Indianapolis: Hackett Publishing Company.

Lewis, David, 1973, Counterfactuals, Cambridge, Massachusetts: Harvard University Press. 
Lewis, David, 1976, "The Paradoxes of Time Travel," American Philosophical Quarterly 13 (1976): 145-52. Reprinted in David Lewis, 1986, Philosophical Papers - Volume II, Oxford, Oxford University Press, pp. 67-80.

Lewis, David, 1979, "Counterfactual Dependence and Time's Arrow," Noûs, 13, 455-76.

McCall, Storrs, 1994, A Model of the Universe, Oxford: Oxford University Press. Mellor, D. H., 1981, Real Time, Cambridge: Cambridge University Press.

Mellor, D. H., 1995, The Facts of Causation, London: Routledge.

Mellor, D. H., 1998, Real Time II, London: Routledge.

Stalnaker, Robert, 1968, "A Theory of Counterfactuals", in Nicholas Rescher (ed.), Studies in Logical Theory, Oxford: Blackwell, pp. 98-112.

Tooley, Michael, 1997, Time, Tense, and Causation, Oxford: Oxford University Press. Reprinted in a revised, paperback edition in 2000.

Tooley, Michael, 2003, "The Stalnaker-Lewis Approach to Counterfactuals," Journal of Philosophy, 100/7, 371-77. 